\title{
Neutralizing Intraspinal Nerve Growth Factor Blocks Autonomic Dysreflexia Caused By Spinal Cord Injury
}

\author{
Natalie R. Krenz, ${ }^{1,2,4}$ Susan O. Meakin, ${ }^{1,3,4}$ Andrei V. Krassioukov, ${ }^{1,2}$ and Lynne C. Weaver ${ }^{1,2,4}$ \\ ${ }^{1}$ Neurodegeneration Research Group, The John P. Robarts Research Institute, Departments of 2Physiology and \\ ${ }^{3}$ Biochemistry, and 4 The Graduate Program in Neuroscience, The University of Western Ontario, London, Ontario, \\ N6A 5 K8 Canada
}

Autonomic dysreflexia is a condition that develops after spinal cord injury in which potentially life-threatening episodic hypertension is triggered by stimulation of sensory nerves in the body below the site of injury. Central sprouting of small-diameter primary afferent fibers in the dorsal horn of the spinal cord occurs concurrently with the development of this condition. We propose a model for the development of autonomic dysreflexia in which increased nerve growth factor (NGF) in the injured cord stimulates small-diameter primary afferent fiber sprouting, thereby magnifying spinal sympathetic reflexes and promoting dysreflexia. We identified this population of afferent neurons using immunocytochemistry for calcitonin gene-related peptide. Blocking intraspinal NGF with an intrathecally-delivered neutralizing antibody to NGF prevented small-diameter afferent sprouting in rats 2 weeks after a high thoracic spinal cord transection. In the same rats, this anti-NGF antibody treatment significantly decreased (by 43\%) the hypertension induced by colon stimulation. The extent of small-diameter afferent sprouting after cord transection correlated significantly with the magnitude of increases in arterial pressure during the autonomic dysreflexia. Neutralizing NGF in the spinal cord is a promising strategy to minimize the life-threatening autonomic dysreflexia that develops after spinal cord injury.

Key words: spinal cord injury; primary afferent fiber sprouting; autonomic dysreflexia; nerve growth factor; antibody to nerve growth factor; calcitonin gene-related peptide
After a spinal cord injury, a condition termed autonomic dysreflexia often develops in humans and rats and is characterized by a potentially life-threatening increase in arterial pressure in response to sensory input entering the spinal cord below the level of the lesion (Osborn et al., 1990; Mathias and Frankel, 1993; Lee et al., 1994; Krassioukov and Weaver, 1995; Maiorov et al., 1997a,b, 1998). Autonomic dysreflexia develops after injuries at or above the midthoracic spinal cord segments. Exaggerated spinal reflexes below the site of injury lead to major excitation of sympathetic vasomotor nerves innervating the splanchnic circulation, producing the episodic hypertension (Maiorov et al., 1997b). This hypertension can reach magnitudes that cause debilitating headaches, seizures, strokes, and even death (Mathias and Frankel, 1992). We have shown that, concurrent with the development of dysreflexia in rats (Maiorov et al., 1997a), afferent fibers that are immunoreactive for calcitonin gene-related peptide (CGRP-IR) increase their central terminal arbors in the dorsal horn of the thoracolumbar cord (Krenz and Weaver, 1998b). These CGRP-IR fibers are unmyelinated afferent C-fibers and lightly myelinated afferent A $\delta$-fibers (Sharkey et al., 1989).

We propose a model for the development of autonomic dysre-

\footnotetext{
Received March 25, 1999; revised June 2, 1999; accepted June 10, 1999.

This work was supported by Grant \#T2679 from the Heart and Stroke Foundation of Ontario. N.R.K. was supported by a Studentship Award from the Medical Research Council of Canada, S.O.M. is a Scholar of the Medical Research Council of Canada, and L.C.W. is a Career Investigator of the Heart and Stroke Foundation of Ontario. We thank Mrs. Barbara Atkinson, Ms. Eilis Hamilton, and Mr. Michael Bygrave for their excellent technical assistance with this work and Drs. Canio Polosa, Arthur Brown, and Stephen Ferguson for their constructive criticisms of this manuscript.

Correspondence should be addressed to Dr. Lynne C. Weaver, Neurodegeneration Research Group, The John P. Robarts Research Institute, P.O. Box 5015, 100 Perth Drive, London, Ontario, N6A 5K8 Canada.

Copyright (C) 1999 Society for Neuroscience $\quad 0270-6474 / 99 / 197405-10 \$ 05.00 / 0$
}

flexia in which increased concentrations of nerve growth factor (NGF) in the spinal cord after spinal cord injury stimulate the sprouting of small-diameter sensory neurons. This sprouting can magnify the afferent component of reflex loops within the spinal cord, exaggerating spinal sympathetic reflexes and promoting autonomic dysreflexia. Many of the requirements of this model and its predictions have been verified by experimentation. First, the time course of sprouting of small-diameter afferent fibers in rats parallels the 2 to 4 week time course of the development of autonomic dysreflexia in these animals (Krassioukov and Weaver, 1995; Maiorov et al., 1997a; Krenz and Weaver, 1998b). Next, CGRP-IR primary afferent neurons express trkA, the highaffinity NGF receptor (Averill et al., 1995), and are responsive to NGF that normally is derived from their targets (Korsching and Thoenen, 1983, 1985; Heumann et al., 1987; Shelton and Reichardt, 1994). Although very little NGF is found in the spinal cord under normal conditions, NGF protein levels near and within a cord injury site rise to a peak at 1 week after injury, and remain increased for up to 4 weeks (Bakhit et al., 1991). Finally, introducing exogenous NGF to the cord of adult animals can stimulate central sprouting of CGRP-IR sensory fibers (Tuszynski et al., 1994, 1996; Christensen et al., 1997; Christensen and Hulsebosch, 1997; Grill et al., 1997b).

We tested the most compelling prediction of our model, that blocking NGF in the injured spinal cord would prevent primary afferent sprouting and block the development of autonomic dysreflexia. To block NGF activity in the injured cord, we administered a neutralizing antibody ( $\mathrm{Ab}$ ) to NGF (rabbit anti-NGF IgG) into the spinal intrathecal space of rats for 2 weeks after transection injury of the spinal cord (SCT). The impact of this treatment was determined by measuring the area of the CGRP-IR afferent arbor in the dorsal horn of the spinal cord (Krenz and Weaver, 
1998b) and by assessing the magnitude of autonomic dysreflexia in the same rats. Changes in arterial pressure were initiated by a balloon distension of the colon that stimulated small-diameter afferent neurons (Maiorov et al., 1997a).

\section{MATERIALS AND METHODS}

\section{Neurite response assay: titration of neutralizing} anti-NGF antibody

A polyclonal antibody to glutaraldehyde-fixed murine $\beta$-NGF was generated in New Zealand white rabbits according to standard procedures. Nonimmune rabbit serum and anti-NGF Ab was purified by protein $\mathrm{G}$ sepharose (Pharmacia, Baie d' Urfe', Quebec, Canada) chromatography. PC12 cells were cultured as previously described (Meakin and MacDonald, 1998). Briefly, 50,000 pheochromocytoma 12 (PC12) cells were seeded in poly-D-lysine-coated 24-well dishes $24 \mathrm{hr}$ before assay. Dilutions of the anti-NGF Ab (1:100-1:40,000) were preincubated with either 1 or $10 \mathrm{ng} / \mathrm{ml} \beta$-NGF (Harlan Bioproducts for Science, Indianapolis, IN) for $1 \mathrm{hr}$ at room temperature prior to cell treatment. Neurite response was determined 48 and $72 \mathrm{hr}$ later and was judged positive if neurite outgrowth was at least one cell body in length. PC12 ${ }^{\mathrm{nnr}}$ cells (Green et al., 1986), stably expressing rat trkB and trkC receptors, were established as previously described (Meakin and MacDonald, 1998). These cell lines were used to determine if the anti-NGF Ab would cross-react with either BDNF (a gift of R. J. Rylett, John P. Robarts Research Institute, London, Ontario, Canada) or NT-3 (a gift of D. Belliveau, University of Western Ontario, London, Ontario, Canada). Using a similar series of dilutions, neurite outgrowth in TrkB- and TrkC-expressing cells in response to $10 \mathrm{ng} / \mathrm{ml}$ of BDNF or NT-3, respectively, was not blocked by the anti-NGF Ab.

\section{Spinal cord transection and delivery of anti-NGF antibody}

All protocols for these experiments were approved by the University of Western Ontario Animal Care Committee in accordance with the policies established in the Canadian Guide to Care and Use of Experimental Animals. Twenty-nine male Wistar rats (Charles River, St. Constant, Quebec, Canada), weighing 300-400 gm, were premedicated and anesthetized as described previously (Krassioukov and Weaver, 1995). The fourth thoracic (T4) spinal cord segment was exposed by a dorsal laminectomy, and the cord was completely transected.

Osmotic mini-pumps (model 2ML2; Alzet Corporation, Palo Alto, CA) were filled with anti-NGF Ab or vehicle, incubated for $4 \mathrm{hr}$ in a $37^{\circ} \mathrm{C}$ water bath, and implanted subcutaneously in the flank. In 19 rats, an intrathecal catheter (PE10) was implanted below the dura mater onto the dorsal surface of the spinal cord caudal to the transection site. The intrathecal catheter was perforated along its length, and the tip was sealed. In the 10 rats tested for dysreflexia, the entire length of the implanted intrathecal catheter was perforated to superfuse the entire cord caudal to the transection with anti-NGF Ab $(0.2 \mathrm{mg} / \mathrm{ml} ; n=6)$ or nonimmune $\operatorname{IgG}(0.2 \mathrm{mg} / \mathrm{ml} ; n=4)$. Both were diluted in sterile artificial CSF (aCSF) and delivered at a rate of $5.4 \mu \mathrm{l} / \mathrm{hr}$. Sufficient anti-NGF Ab was used to neutralize the maximal concentration of NGF protein (70 $\mathrm{ng} / \mathrm{gm}$ spinal cord tissue) found in the cord at the injury site (Bakhit et al., 1991). Anti-NGF Ab was delivered in the same manner to one additional rat that was used to test the diffusion of the antibody into the cord. In eight other rats, only the final $1.5 \mathrm{~cm}$ of the catheter was perforated so that $\sim 4-5$ spinal segments would be infused with antiNGF Ab $(0.03 \mathrm{mg} / \mathrm{ml})$ or sterile aCSF, both at a rate of $5.4 \mu \mathrm{l} / \mathrm{hr}$. In this experiment, the concentration of anti-NGF Ab used was estimated to be ten times in excess of that necessary to neutralize the NGF (2-7 ng/gm spinal cord tissue) found in the lumbar cord after injury (Bakhit et al., 1991). At the end of the 2 week infusion period and immediately before perfusion of the rats, the pumps were removed and checked for residual volume. The pumps were either completely empty or contained, at most, $0.2 \mathrm{ml}$ of fluid.

In eight rats, a subcutaneous catheter (PE100) delivered anti-NGF Ab $(0.4 \mathrm{mg} / \mathrm{ml}$ at $5.4 \mu \mathrm{l} / \mathrm{hr})$ or sterile physiological saline in the vicinity of the right knee joint. This dose was estimated to be at least ten times that needed to neutralize NGF found in the affected skin $(20 \mathrm{ng} / \mathrm{gm}$ wet weight) (Constantinou et al., 1994). The volume in the pumps at the end of each experiment was negligible, as described above.

After all surgical preparations, the incisions were closed, and the animals received postoperative care as described previously (Krassioukov and Weaver, 1995). All animals recovered for 2 weeks, during which time the mini-pumps provided a steady infusion of antibody or vehicle.

\section{Assessing autonomic dysreflexia}

Thirteen days after SCT, carotid cannulas were implanted in the 10 rats used to test dysreflexia as described previously (Maiorov et al., 1997a). The rats recovered from anesthesia for at least $4 \mathrm{hr}$ before testing. Autonomic dysreflexia was initiated by balloon distension of the colon (Maiorov et al., 1997a). The distension was maintained for a total of 1 min. Heart rate and mean and pulsatile arterial pressure were monitored displayed on a Grass Instruments (Quincy, MA) polygraph. Measurements were taken the day of arterial cannulation and on the following day. Two or three trials were repeated each day, with an intertrial interval of at least $10 \mathrm{~min}$. The investigator testing dysreflexia was not informed whether individual subject rats had received anti-NGF Ab or nonimmune $\mathrm{IgG}$.

\section{Immunocytochemistry}

Perfusion of rats. Two weeks after SCT, the rats to be assessed for CGRP-IR and the one rat to be assessed for diffusion of anti-NGF Ab into the cord were anesthetized with $2.5 \mathrm{gm} / \mathrm{kg}$ urethane and perfused transcardially as described previously (Krenz and Weaver, 1998b). The position of the intrathecal catheter was verified by inspection, to note the cord segments that were superfused, and the spinal cord was removed. In addition, four control rats that had not been subjected to SCT were perfused, and the spinal cords removed. The thoracic and lumbar (L) segments of the spinal cord were removed and divided into four portions containing segments T1-3, T6-9, T10-13, and L1-5. Tissue was postfixed, cryoprotected, and sectioned into $30 \mu \mathrm{m}$ transverse sections as described previously (Krenz and Weaver, 1998b). Tissue from the rat to be assessed for anti-NGF Ab diffusion was sectioned transversely at 30 $\mu \mathrm{m}$ and thaw-mounted onto slides. In addition, a piece of cerebellum from this rat and a T9-12 thoracic spinal cord from an intact, untreated rat were sectioned and used as negative controls. Binding of the neutralizing anti-NGF $\mathrm{Ab}$ to cells in spinal cord sections was assessed in two rats at 1 week after SCT. These rats were anesthetized and perfused with tissue culture medium (DMEM) followed by $2 \%$ paraformaldehyde and $0.2 \%$ parabenzoquinone. The T4-5 and scar portion of the thoracic spinal cord was removed, post-fixed for $2 \mathrm{hr}$, then cryoprotected overnight in sucrose. The tissue was cut with a cryostat into $10 \mu \mathrm{m}$ horizontal sections and thaw-mounted onto gelatin-coated slides.

Processing for CGRP-IR. Details of processing for CGRP-IR have been reported previously (Krenz and Weaver, 1998b). Briefly, floating sections were reacted at room temperature in rabbit anti-CGRP (diluted 1:10,000; Peninsula Laboratories, Belmont, CA) for 48-60 hr. They were next incubated overnight at room temperature in goat anti-rabbit $\mathrm{IgG}$, conjugated to biotin (diluted 1:200; Jackson ImmunoResearch, Mississauga, Ontario, Canada). Finally the tissue was incubated with rhodamine-lissamine conjugated to streptavidin (diluted 1:150; Jackson ImmunoResearch) for $4 \mathrm{hr}$. The sections were mounted onto slides and coverslipped.

Processing for NGF-IR. The thaw-mounted horizontal cord sections were processed for NGF-IR in the manner previously described (Conner and Varon, 1992; Krenz and Weaver, 1998b). Briefly, sections were incubated in anti-NGF Ab from the stock used as a neutralizing antibody for $\sim 60 \mathrm{hr}$. The anti-NGF Ab was diluted 1:2000. The tissue was then incubated for $3 \mathrm{hr}$ in 1:500 biotin-conjugated goat anti-rabbit antibody (Vector Laboratories, Burlingame, CA) in TPBS-X and for 90 min with an avidin-biotin-peroxidase agent (1:250 dilution; ABC Elite; Vector Laboratories). Immunoreactivity was revealed with a nickel-enhanced diaminobenzidine (NiDAB) reaction. No immunoreactivity was found in tissue sections processed in the absence of the primary antibody (antiNGF Ab).

Processing to detect anti-NGF Ab penetration into the spinal cord. In this analysis, the neutralizing anti-NGF $\mathrm{Ab}$ that had diffused into the spinal cord was the rabbit antigen. As described above for CGRP-IR, the thaw-mounted sections of cord and cerebellum were incubated overnight at room temperature in goat anti-rabbit IgG, conjugated to biotin (diluted 1:200; Jackson ImmunoResearch). The tissue was then incubated with rhodamine-lissamine conjugated to streptavidin (diluted 1:150; Jackson ImmunoResearch) for $4 \mathrm{hr}$.

\section{Data and statistical analyses}

The cumulative area of CGRP-immunofluorescent fibers in laminae III, $\mathrm{IV}$, and $\mathrm{V}$ of the spinal cord was obtained using the morphometry 


\begin{tabular}{llll}
\hline $\begin{array}{l}\text { Table 1. Neurite response assay in PC12 cells: titration of neutralizing } \\
\text { anti-NGF Ab }\end{array}$ & & & \\
Dilution of Anti-NGF & $10 \mathrm{ng} / \mathrm{ml}$ & $1 \mathrm{ng} / \mathrm{ml}$ & $1 \mathrm{ng} / \mathrm{ml} \beta$-NGF \\
$\mathrm{Ab}(\mathrm{new} \mathrm{Ab})$ & $\beta$-NGF & $\beta$-NGF & $(\mathrm{Ab}$ after $14 \mathrm{~d}$ in pump) \\
\hline None & + & + & + \\
$1: 100$ & - & - & - \\
$1: 200$ & - & - & - \\
$1: 500$ & - & - & - \\
$1: 1000$ & - & - & - \\
$1: 2000$ & + & - & - \\
$1: 5000$ & + & - & - \\
$1: 10,000$ & + & - & $+/-$ \\
$1: 20,000$ & + & + & $\mathrm{NT}$ \\
$1: 40,000$ & + & + & $\mathrm{NT}$
\end{tabular}

+ indicates neurite outgrowth of at least one cell body length. NT, Not tested. Identical curves were generated in three or four independent assays.

program of the MCID system (Imaging Research, St. Catharines, Ontario, Canada) as described previously (Krenz and Weaver, 1998b). The investigator had no knowledge of the treatment applied to the spinal cord during these measurements. Three factorial ANOVAs were used to analyze the areas of CGRP-IR fibers in rats that were treated with anti-NGF Ab or vehicle (1) along the entire extent of the cord caudal to the transection, (2) in a limited cord portion caudal to the transection, and (3) subcutaneously. Tukey's protected $t$ test was used for comparisons between group means after all ANOVAs (Sokol and Rohlf, 1981). Student's $t$ tests were performed to make comparisons of physiological responses between groups of animals receiving continuous superfusion of nonimmune $\mathrm{IgG}$ and those superfused with anti-NGF Ab (Sokol and Rohlf, 1981). Comparisons between the two groups were made of baseline heart rate, arterial pressure, and their respective changes during colon distension. Linear regression analysis was done to correlate areas of CGRP-IR in the dorsal horn with the changes in arterial pressure during episodic hypertension in the same rats (Sokol and Rohlf, 1981). Differences were considered significant when $p<0.05$.

\section{RESULTS}

\section{Characteristics of the neutralizing antibody to NGF}

Before testing the Ab to NGF in vivo, we determined an effective concentration (EC) needed to neutralize NGF in an in vitro neurite response assay. Specifically, PC12 cells were assayed for NGF-dependent neurite outgrowth in the presence of serial dilutions of the Ab. Accordingly, we found that a 1:1000 dilution of the anti-NGF Ab prevented neurite outgrowth in PC12 cells in response to $10 \mathrm{ng} / \mathrm{ml} \mathrm{NGF} \mathrm{(Table} \mathrm{1,} \mathrm{Fig.} \mathrm{1).} \mathrm{Likewise,} \mathrm{a} \mathrm{1:10,000}$ dilution prevented neurite outgrowth in response to $1 \mathrm{ng} / \mathrm{ml} \mathrm{NGF}$ (Table 1). To test the specificity of the Ab, PC12 ${ }^{\mathrm{nnr}}$ cells [that do not express trkA receptors (Green et al., 1986)] were generated to express trkB and trkC receptors for brain-derived neurotrophic factor (BDNF) and neurotrophin-3 (NT-3), respectively. Using a similar dose-response curve, we found that no concentration of the $\mathrm{Ab}$ could block neurite outgrowth in response to $10 \mathrm{ng} / \mathrm{ml}$ of BDNF or NT-3, indicating a specificity of the Ab for NGF.

The anti-NGF Ab was also tested immunocytochemically on sections from injured rat spinal cord to determine if it labels the same cells that we have previously identified as NGF-IR using an affinity-purified antibody (Conner and Varon, 1992; Krenz and Weaver, 1998a). When used for immunocytochemistry, the neutralizing anti-NGF Ab strongly stained macrophages (Fig. 2a,c) and Schwann cells in the dorsal root entry zones and around blood vessels (Fig. 2b,d). The neutralizing anti-NGF Ab did not bind to cell types other than those we previously identified with an affinity-purified antibody to NGF (Krenz and Weaver, 1998a),

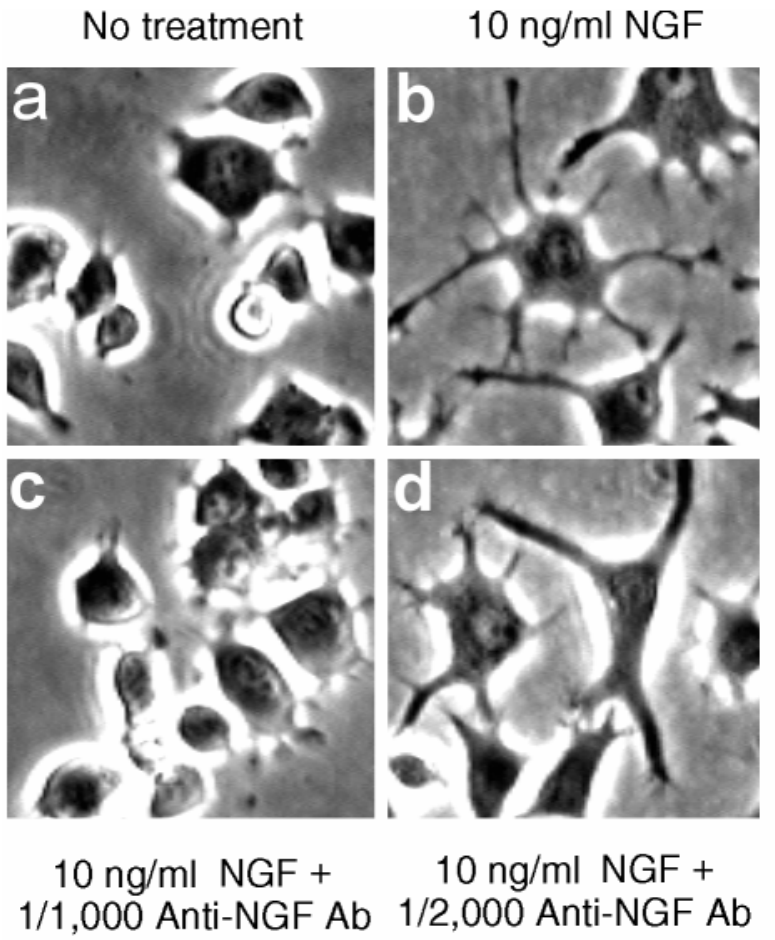

Figure 1. PC12 cell neurite response assay. PC12 cells were cultured for $48 \mathrm{hr}$ without NGF treatment $(a)$ or with $10 \mathrm{ng} / \mathrm{ml} \mathrm{NGF}(b)$, with 10 $\mathrm{ng} / \mathrm{ml}$ NGF plus anti-NGF Ab $(1: 1000 ; c)$ or with $10 \mathrm{ng} / \mathrm{ml}$ NGF plus anti-NGF Ab $(1: 2000 ; d)$.

thereby demonstrating lack of nonspecific binding to spinal cord cells.

\section{Intrathecal delivery of antibody to NGF blocks afferent fiber sprouting}

We infused the anti-NGF $\mathrm{Ab}$ into the entire thoracolumbar intrathecal space caudal to a SCT at T4 to determine whether neutralizing intraspinal NGF for 2 weeks prevents CGRP-IR afferent fiber sprouting. Immunocytochemical detection of the distribution of the anti-NGF $\mathrm{Ab}$ in the spinal cord in a rat revealed that it diffused into all the thoracolumbar segments. It was distributed throughout the white and gray matter of the cord in T6-9 and T10-13 and, in L1-5, it penetrated $\sim 200 \mu \mathrm{m}$ from the dorsal surface, extending from lamina I-VII (Fig. $3 a$ ). No immunofluorescence was found in the spinal cord of an intact, untreated rat (Fig. $3 b$ ) or the cerebellum of the anti-NGF Abtreated rat (Fig. 3c).

Although CGRP-IR fibers and terminals are heavily distributed in laminae I and II of the dorsal horn, only laminae III-V were analyzed because interneurons that likely receive input from primary afferent neurons to mediate spinal sympathetic reflexes are located in these laminae (Joshi et al., 1995; Clarke et al., 1998). The area of these fibers in laminae III-V was quantified by measuring their area within a standard region of the dorsal horn in transverse sections of spinal cord. This area increased markedly at 2 weeks after SCT (Fig. 4) as we reported previously (Krenz and Weaver, 1998b), and the increase was blocked by intrathecal infusion of the anti-NGF $\mathrm{Ab}$. In the spinal cord of intact rats, CGRP-IR fibers and terminals in the dorsal horn extended sparsely into laminae III-V (Fig. 4a,d). In the SCT 

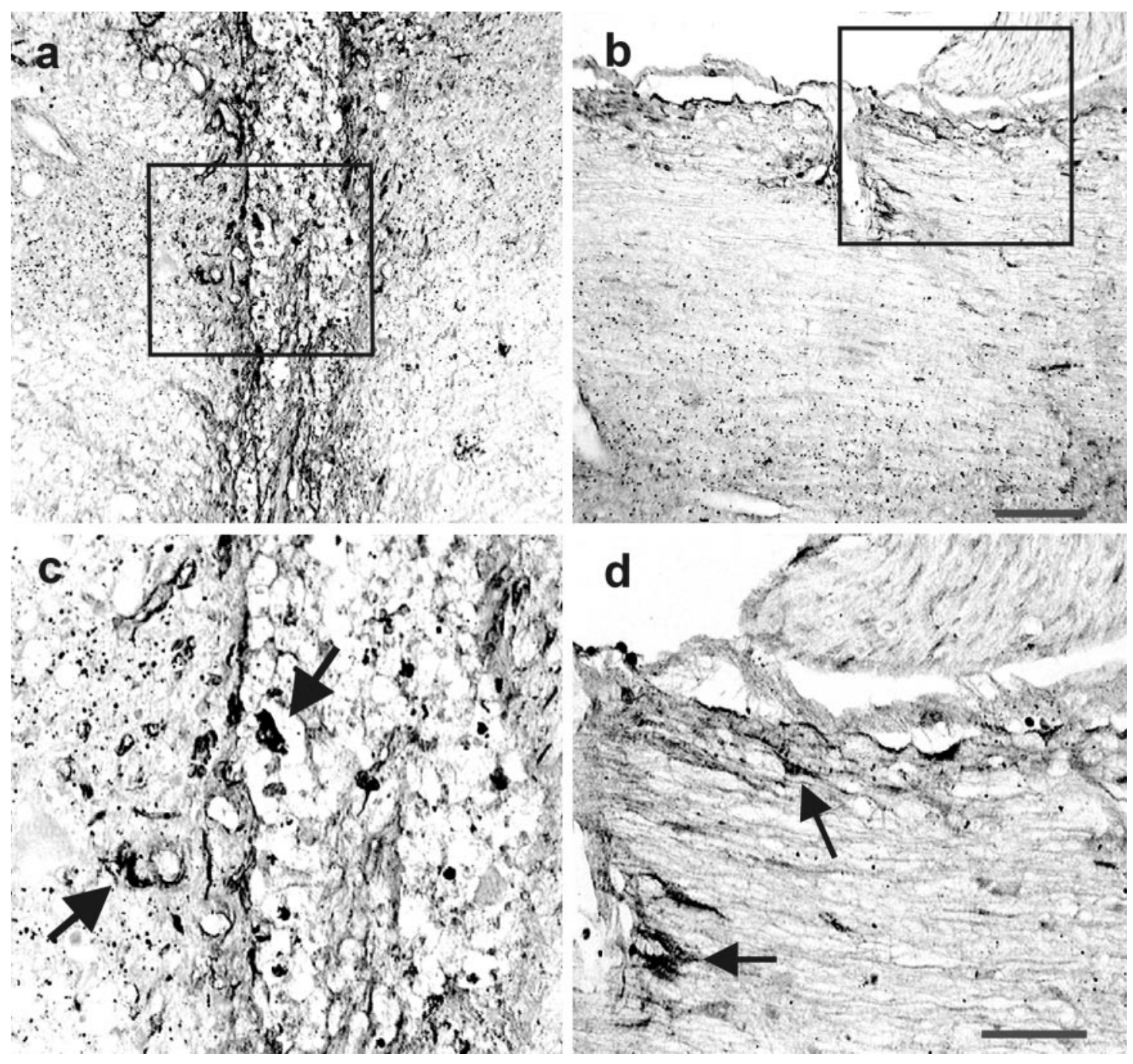

Figure 2. Digital photomicrographs of horizontal sections of spinal cord at the injury site in the thoracic segment immunostained using the anti-NGF $\mathrm{Ab}$. Sections were taken from a rat $7 \mathrm{~d}$ after SCT at T4. Panels $a$ and $c$ depict NGF-IR macrophages at the transection site. Panels $b$ and $d$ illustrate NGF-IR Schwann cells at the dorsal root entry zone subpial rim and near an arteriole. The boxes on panels $a$ and $b$ delineate the region depicted in panels $c$ and $d$, respectively. Scale bars: $a, b, 100 \mu \mathrm{m} ; c, d, 50 \mu \mathrm{m}$. Arrows point to examples of immunoreactive cells.

animals that received only intrathecal nonimmune rabbit $\mathrm{IgG}$, the area of CGRP-IR fibers in laminae III-V of all cord portions was significantly (50-75\%) larger than in the corresponding cord segments in the intact rats (Figs. $4 b, e, 5$ ). In the SCT rats receiving anti-NGF $\mathrm{Ab}$ treatment, this enlargement of the afferent arbor was completely blocked (Figs. 4c, $f, 5$ ). The area of CGRP-IR fibers in the cord caudal to the transection after anti$\mathrm{NGF} \mathrm{Ab}$ was significantly less than in corresponding cord portions of animals receiving nonimmune $\mathrm{IgG}$ and was the same as that in intact rats (Fig. 5). Anti-NGF Ab treatment did not block the enlargement of the afferent arbor in spinal segments rostral to the transection (Fig. 5). This was the anticipated result because the anti-NGF Ab should not have reached cord segments rostral to the SCT.

After the 2 week incubation of the $\mathrm{Ab}$ in the implanted minipump, the effective concentration was redetermined. The same dose-response assay used to assess the $\mathrm{Ab}$ before in vivo incubation revealed that a 1:5000 dilution of the $\mathrm{Ab}$ was still effective in blocking the neurite response to $1 \mathrm{ng} / \mathrm{ml}$ NGF (Table 1). Thus, the $\mathrm{EC}_{50}$ had decreased by, at most, $50 \%$ during the in vivo treatment paradigm.

\section{Limited intrathecal delivery of antibody to NGF has local effects on afferent sprouting}

A second group of SCT rats was tested to determine whether a local application of anti-NGF Ab in only one portion of the cord caudal to the transection would affect sprouting only in that region of the cord. In this experiment, an animal served as its own control because afferent sprouting in cord regions receiving Ab could be compared to sprouting in regions that did not receive antibody. This design avoided possible interanimal variability. Two weeks after SCT, rats received an intrathecal infusion of anti-NGF Ab or aCSF delivered only to four or five segments of the cord caudal to the transection. Within individual rats, the portions of cord superfused with anti-NGF Ab contained a smaller area of CGRP-IR fibers in laminae III-V than portions that were not superfused (Table 2). In addition, in portions of the cord superfused with anti-NGF Ab, laminae III-V had a decreased area of CGRP-IR fibers compared to the area in the same spinal cord portions in rats superfused with aCSF (Table 2). The area of CGRP-IR in caudal portions receiving aCSF did not differ from caudal portions receiving no superfusion of aCSF (Table 2). The areas of CGRP-IR fibers in the segments rostral to the transection were similar in 

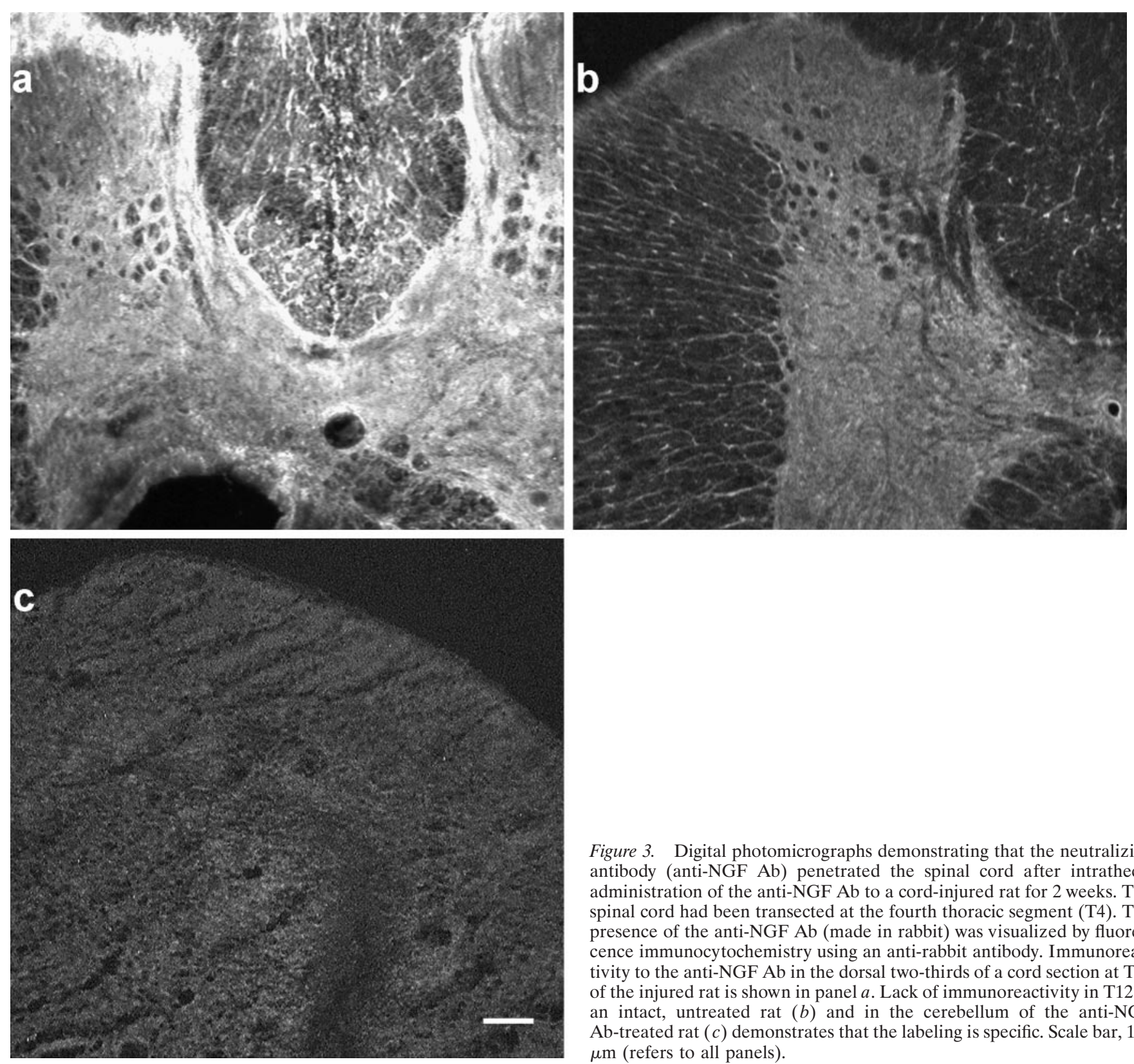

Figure 3. Digital photomicrographs demonstrating that the neutralizing antibody (anti-NGF $\mathrm{Ab}$ ) penetrated the spinal cord after intrathecal administration of the anti-NGF Ab to a cord-injured rat for 2 weeks. The spinal cord had been transected at the fourth thoracic segment (T4). The presence of the anti-NGF Ab (made in rabbit) was visualized by fluorescence immunocytochemistry using an anti-rabbit antibody. Immunoreactivity to the anti-NGF Ab in the dorsal two-thirds of a cord section at T12 of the injured rat is shown in panel $a$. Lack of immunoreactivity in T12 of an intact, untreated rat $(b)$ and in the cerebellum of the anti-NGF Ab-treated rat $(c)$ demonstrates that the labeling is specific. Scale bar, 100 $\mu \mathrm{m}$ (refers to all panels).

aCSF-treated $\left(10,750 \pm 1114 \mu \mathrm{m}^{2}\right)$ and anti-NGF Ab-treated $\left(9950 \pm 1181 \mu \mathrm{m}^{2}\right)$ spinal rats. Therefore, the effects of intrathecal anti-NGF Ab appeared to be caused by a local spinal action of the antibody.

\section{Subcutaneous delivery of antibody to NGF does not block afferent sprouting}

In the experiments described above, afferent sprouting occurred unabated rostral to the SCT, and in untreated caudal regions, suggesting that the anti-NGF Ab had acted in the cord rather than by leaking into the circulation to neutralize peripheral NGF. These results did not address another important question, the potential role of peripherally produced NGF in sprouting of central afferent arbors after SCT. Therefore, anti-NGF Ab was delivered subcutaneously to hindlimb targets of the lumbar sensory nerves for 2 weeks, and central sprouting of CGRP-IR afferent fibers from the limb was assessed. This method of antiNGF Ab delivery effectively blocks peripheral nerve sprouting triggered by peripheral sources of NGF (Diamond et al., 1992). Unilateral subcutaneous infusion of anti-NGF Ab into the right hindlimb had no effect on primary afferent fiber sprouting in the ipsilateral L4-5 spinal cord in rats 2 weeks after SCT. These lower lumbar segments contain terminations of small-diameter afferent neurons innervating the hindlimb. No difference in area of CGRP-IR afferent arbors was observed between left (6915 \pm $\left.624 \mu \mathrm{m}^{2}\right)$ and right $\left(7301 \pm 455 \mu \mathrm{m}^{2}\right)$ dorsal horns of these lumbar spinal segments in anti-NGF Ab-treated rats. Likewise, no difference in the dorsal horn area of CGRP-IR was found between animals receiving anti-NGF $\mathrm{Ab}$ (above) and animals receiving saline (left: $9520 \pm 1752 \mu \mathrm{m}^{2}$, right: $7738 \pm 1474 \mu \mathrm{m}^{2}$ ).

\section{Intrathecal delivery of antibody to NGF blocks autonomic dysreflexia}

To evaluate whether anti-NGF Ab treatment would ameliorate autonomic dysreflexia, arterial pressure and heart rate responses to colon distension were assessed 2 weeks after SCT at T4. This 


\section{Control}
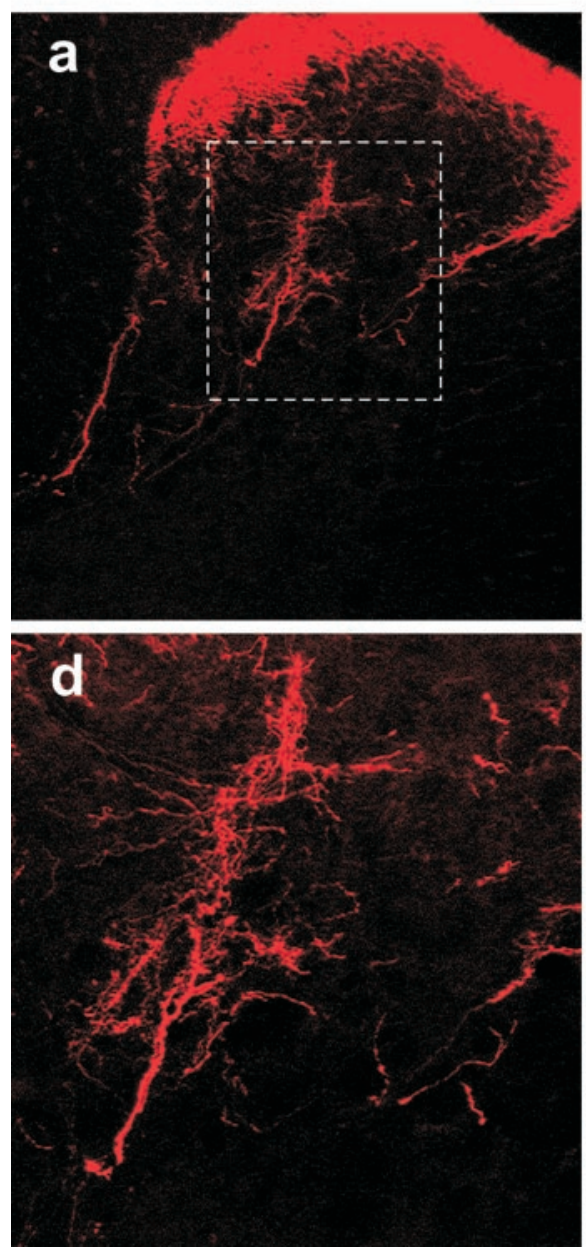

2 week SCT- IgG
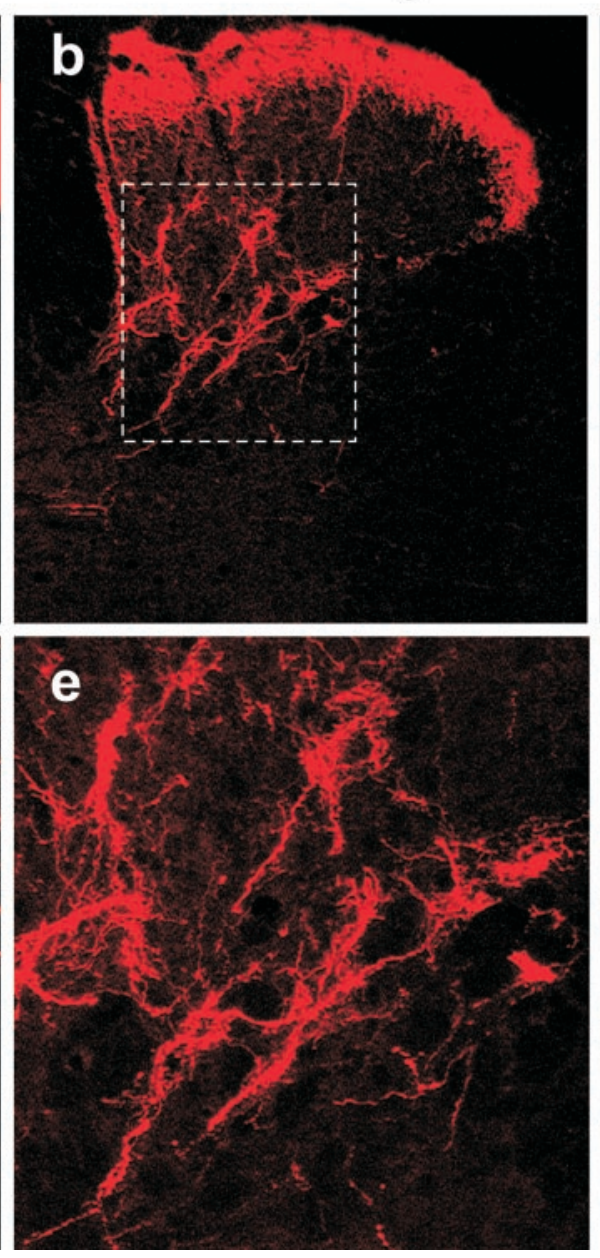

\section{2 week SCT-anti-NGF Ab}
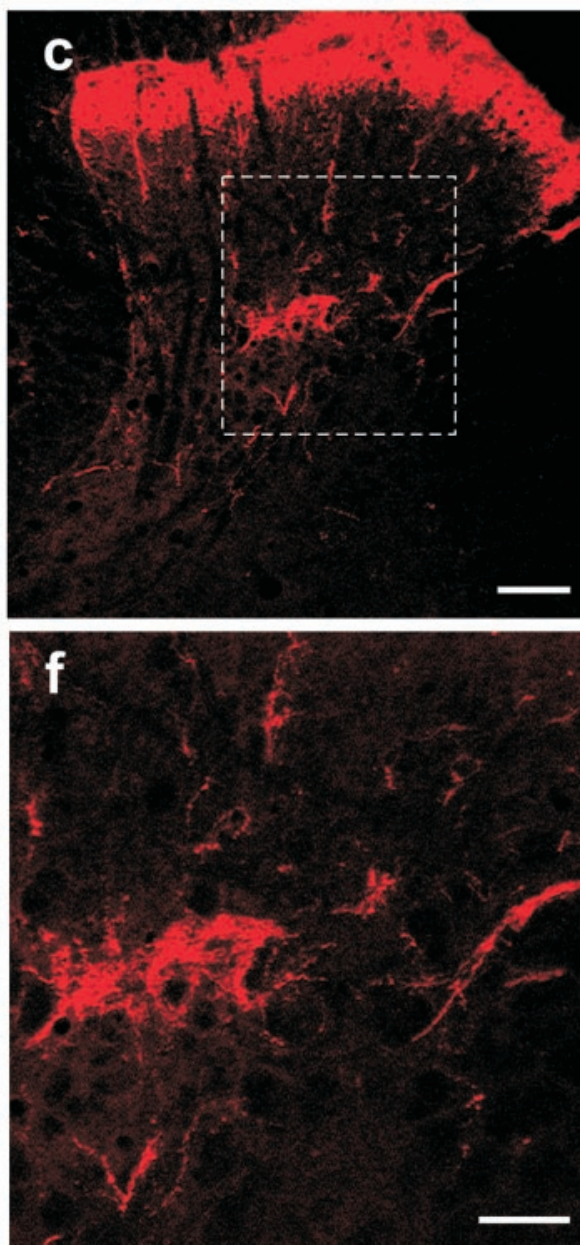

Figure 4. Digital photomicrographs of CGRP-IR fibers in the dorsal horn of control intact rats $(a, d)$, rats 2 weeks after cord injury that received an intrathecal infusion of nonimmune rabbit $\operatorname{IgG}(b, e)$, and rats 2 weeks after cord injury that received intrathecal infusion of anti-NGF Ab $(c, f)$. Tissue sections are from T6. Panels $d-f$ are magnifications of laminae III-V from panels $a-c$. The boxes on panels $a-c$ indicate the regions shown in the higher magnification photomicrographs. Scale bars: $a-c, 100 \mu \mathrm{m} ; d-f, 50 \mu \mathrm{m}$.

experimental stimulus reliably produces well-characterized autonomic dysreflexia in rats after SCT at T4 (Maiorov et al., 1997a). This study was performed in the same rats in which anti-NGF Ab or nonimmune IgG was delivered for 2 weeks to the entire cord caudal to the transection, and afferent fiber sprouting was evaluated (Figs. 4, 5). Baseline arterial pressure in the two groups of rats was similar, whereas heart rate was lower by $\sim 45$ beats/min in the anti-NGF Ab-treated rats (Table 3, Fig. 6). Colon distension initiated a marked increase in the mean arterial pressure of $\sim 30$ $\mathrm{mmHg}$ in the nonimmune IgG-treated rats (Table 3, Fig. 6). In contrast, the increase in arterial pressure was significantly reduced to $17 \mathrm{mmHg}$ in the animals treated with anti-NGF $\mathrm{Ab}$. Reflex decreases in heart rate were similar in both groups (57-59 beats/min). The increased arterial pressure in the nonimmune IgG-treated rats outlasted the colon distension stimulus by $\sim 1$ min, whereas the response tended to be abbreviated in the antiNGF Ab-treated rats (Table 3). The diminished pressor responses to colon distension in the anti-NGF Ab-treated animals paralleled the lack of afferent fiber sprouting in their spinal cords (Fig. 5). Conversely, the undiminished afferent fiber sprouting in the nonimmune IgG-treated rats (Fig. 5) corresponded with the full development of autonomic dysreflexia that we have described previously (Maiorov et al., 1997a). Analyzing the changes in arterial pressure in both groups of rats relative to the area of their T6-9 afferent arbor demonstrated significant correlation $(r=$ $0.80)$. The correlation was made to the afferent fiber areas in the T6-9 segments, because these segments contain the major population of preganglionic neurons controlling the splanchnic visceral circulation, an important constricting vascular bed in the episodic hypertension (Mathias and Frankel, 1993; Krassioukov and Weaver, 1995).

\section{DISCUSSION}

\section{Validation of the model for autonomic dysreflexia}

The results of this study provide important support for the model that NGF-mediated sprouting of the small-diameter afferent fibers is largely responsible for the episodic hypertension that occurs after cord injury. Several predictions were substantiated. Superfusion of anti-NGF Ab over the spinal cord caudal to a transection injury prevented the central sprouting of these primary afferent fibers throughout the thoracic and lumbar spinal cord. In contrast, injection of anti-NGF Ab into the subcutaneous tissue of the hindlimb had no effect on the sprouting after cord injury. The intraspinal sequestering of NGF had an important 


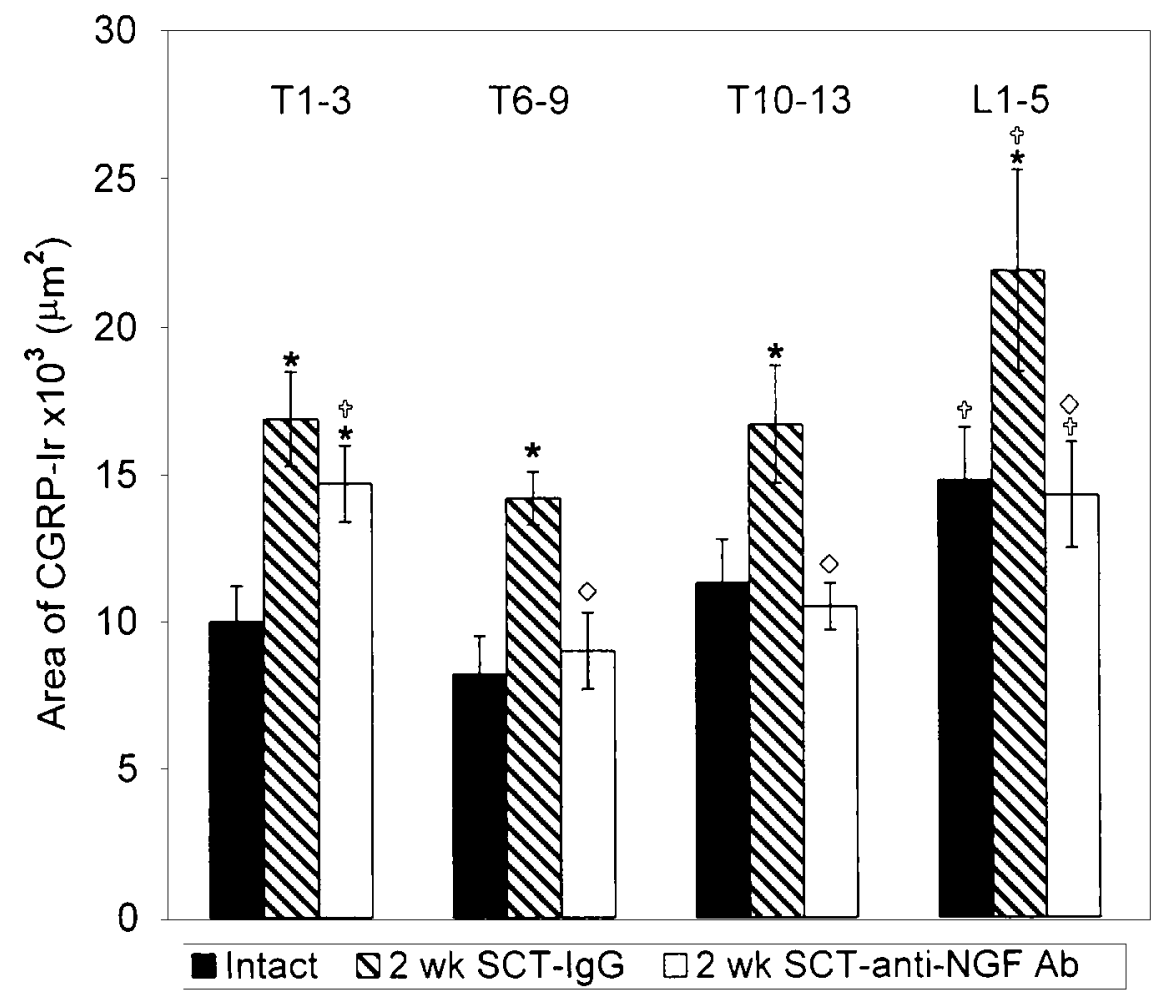

Figure 5. Mean areas of CGRP-IR fibers in laminae III-IV of the thoracic $(T)$ and lumbar $(L)$ spinal segments in rats with no spinal cord injury (intact) and in rats 2 weeks after spinal cord transection $(S C T)$. After SCT, rats received nonimmune rabbit IgG or anti-NGF Ab intrathecally. The CGRP-IR areas in rats treated with rabbit IgG increased significantly (asterisk) compared with intact controls; the CGRP-IR areas in rats treated with anti-NGF $\mathrm{Ab}$ were significantly smaller than areas in the same cord segments of rats treated with rabbit IgG (open diamond); the CGRP-IR areas in T1-3 and L1-5 of some spinal rats were larger than the area in T6-9 within the same treatment group (open cross). Each treatment group contained four rats. In the rabbit IgG-treated group, samples could not be obtained for T10-L5 in one rat because of catheter-induced damage to the cord.

\begin{abstract}
Table 2. Area in square micrometers (mean \pm SEM) of CGRP-IR fibers in laminae III-V of rats treated with continuous intrathecal infusion of anti-NGF $\mathrm{Ab}$ or vehicle in one portion of spinal cord caudal to the cord transection for 2 weeks

\begin{tabular}{lll} 
Spinal cord caudal to injury & Not superfused & Superfused \\
\hline $\begin{array}{l}\text { Rats receiving aCSF } \\
(n=4)\end{array}$ & $6483 \pm 257(7)$ & $8699 \pm 1182(5)$ \\
$\begin{array}{l}\text { Rats receiving anti-NGF Ab } \\
(n=4)\end{array}$ & $7798 \pm 550(8)$ & $4950 \pm 579^{*, * *}(4)$ \\
& &
\end{tabular}
\end{abstract}

Pooled SE $=329$.

*Values are significantly different from aCSF controls.

**Values are significantly different from other caudal cord portions in group.

$n=$ number of rats in each group.

$(\mathrm{x})=$ number of cord portions included in each category. Usually, one caudal portion of spinal cord was superfused, and two portions were not superfused.

functional outcome, significantly reducing the development of autonomic dysreflexia.

\section{NGF can stimulate sprouting in the CNS}

Other experiments have shown that the presence of NGF in the spinal cord can lead to sprouting of CGRP-IR fibers. NGFexpressing fibroblasts implanted into the cord induce sprouting of these fibers (Tuszynski et al., 1994, 1996; Grill et al., 1997b). Mice that express a NGF transgene in oligodendrocytes have ectopic CGRP-IR fibers in the white matter of their spinal cords (Ma et al., 1995). Conversely, a study of pain mechanisms after cord injury also showed, like our observation, that treatment with an antibody to NGF prevented CGRP-IR fibers from sprouting in the dorsal horn after spinal hemisection at T13 (Christensen and Hulsebosch, 1997). CGRP-IR afferent fibers sprout in the dorsal horn in this model of cord injury-induced allodynia and hyperalgesia. However, this study did not describe a physiological outcome of that blockade of afferent sprouting.

\section{The effect of anti-NGF antibody on autonomic dysreflexia}

The blockade of sprouting by intrathecal anti-NGF Ab was associated with an altered physiological response to SCT. Autonomic dysreflexia, which is well developed in rats 2 weeks after SCT, was markedly reduced by this treatment. The increase in mean arterial pressure in response to colon distension in anti-NGF Abtreated animals was reduced by $43 \%$ compared to nonimmune IgG-treated animals. Our study suggests a causal relationship between small-diameter CGRP-IR afferent sprouting and autonomic dysreflexia, because the suppression of both by anti-NGF $\mathrm{Ab}$ treatment was well correlated. Other observations also imply a causal relationship between afferent sprouting and dysreflexia. First, the time course of development of small-diameter afferent sprouting is similar to that of autonomic dysreflexia (Krassioukov and Weaver, 1995; Maiorov et al., 1997a). Second, the magnitude of a spinal sympathetic reflex is known to increase when the afferent input to the spinal cord is increased (Koizumi et al., 1970; Sato and Schmidt, 1973).

Although intrathecal anti-NGF Ab treatment significantly reduced the hypertensive response, the treatment did not entirely eliminate dysreflexia. This incomplete blockade of dysreflexia, despite complete blockade of afferent sprouting, indicates that other mechanisms, independent of the actions of NGF on smalldiameter afferent neurons, contribute to the development of autonomic dysreflexia. Indeed, possible actions of NGF on other spinal cord cells may not have been completely blocked. In addition, sprouting of myelinated afferent fibers unresponsive to NGF, sprouting of interneurons, alterations in central or peripheral neurotransmission, and changes in baroreceptor reflexes could also contribute to exaggerated reflexes (Lee et al., 1994). Finally, colon distension could initiate changes in gastrointestinal motility, indirectly activating vagal afferent fibers projecting to the brainstem (Janig, 1996). This activation could lead to vagally- 
Table 3. Mean arterial pressure (MAP) and heart rate (HR) before and during colon distension in rats that received continuous intrathecal infusion (T6-L5) of anti-NGF Ab or non-immune IgG for 2 weeks after SCT

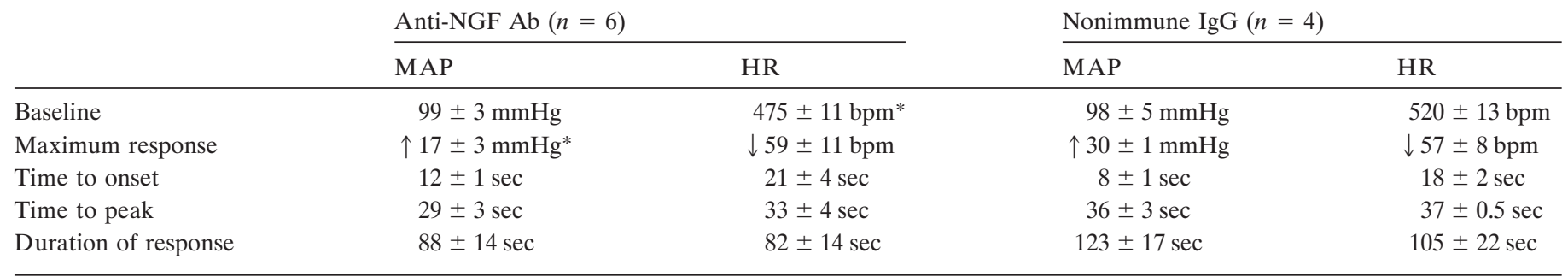

*Values are significantly different from nonimmune IgG controls.

$n=$ number of rats in each group.

bpm, Beats per minute.
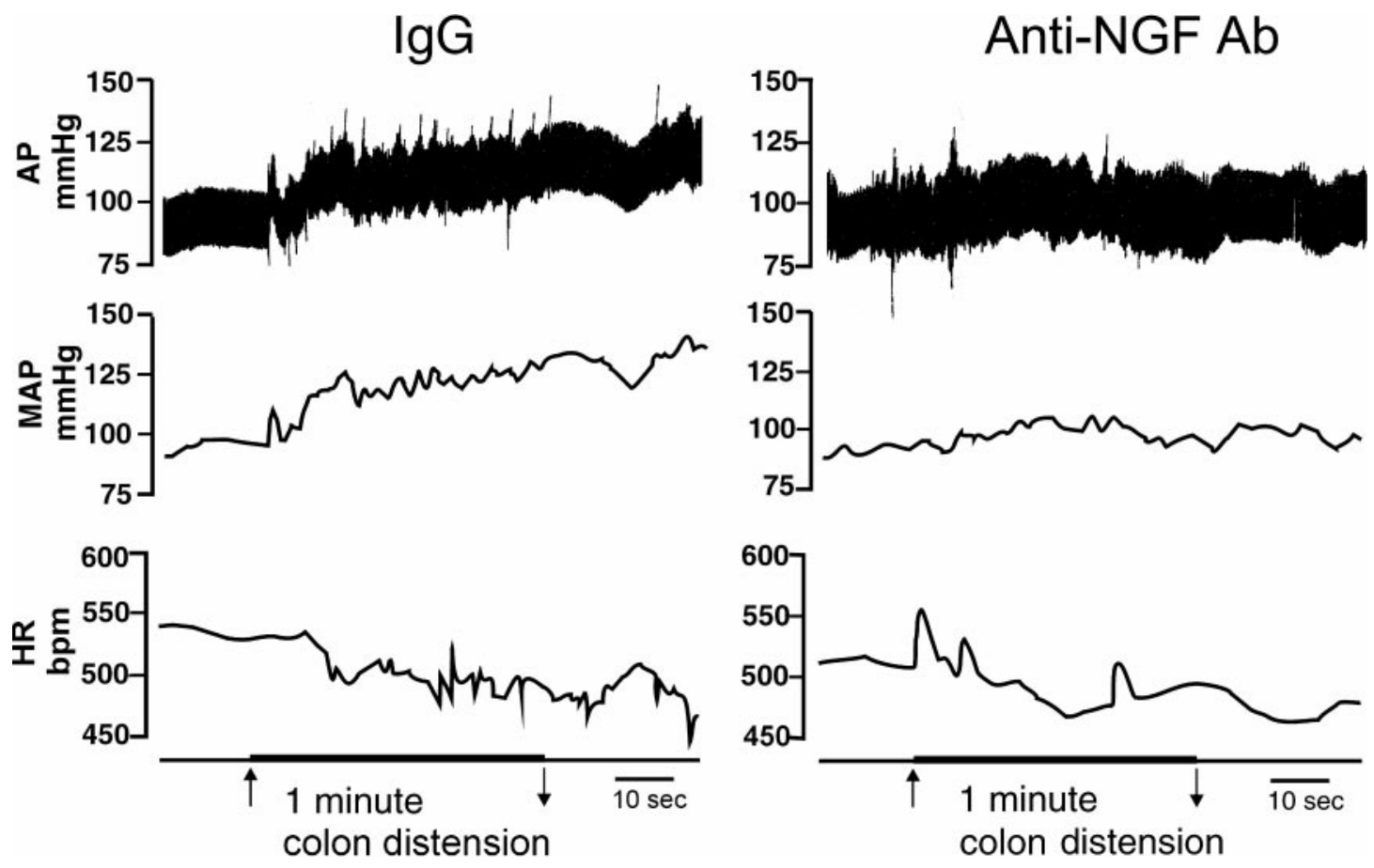

Figure 6. Pulsatile arterial pressure $(A P)$, mean arterial pressure $(M A P)$, and heart rate $(H R)$ measurements in two rats 2 weeks after cord transection that received nonimmune IgG or anti-NGF Ab. Colon distension for 1 min (between arrows) stimulated an increase in AP and MAP and a decrease in HR.

mediated effects on the heart and to changes in sympathetic outflow in cord segments rostral to the injury site (Pittam et al., 1988). If such vago-vagal or vago-sympathetic reflexes were excitatory after cord injury, they could have contributed to the increases in arterial pressure during autonomic dysreflexia and would not have been blocked by our anti-NGF treatment. After an incomplete injury of the cord, such supraspinally mediated reflexes might even impact on the segments caudal to the injury.

The partial blockade accomplished in our study is actually an ideal effect, because total blockade of dysreflexia is not the desired outcome of treatment in humans. The symptoms of minor episodes of dysreflexia, such as modest changes in arterial pressure, heart rate slowing, and sweating are the few indicators to cord-injured people that sensory input from their lower body has changed, either because of a normal physiological process or to disordered function (Mathias and Frankel, 1992). Partial blockade of dysreflexia would reduce the severity of hypertension that renders it incapacitating and life-threatening while permitting cord-injured people some remaining awareness of changes ongoing in their body below their injury.

Some additional effects were seen in rats treated with intrathecal anti-NGF Ab. Animals receiving anti-NGF Ab did not develop the elevated heart rates typically observed after a T4 SCT (Krassioukov and Weaver, 1995; Maiorov et al., 1997a). The nonimmune IgG-treated rats had increased rates (>500 bpm), but those treated with antibody to NGF did not. Neurons controlling heart rate (near segment T2) have lost no input with a T4 injury and were not exposed to anti-NGF Ab. We speculate that the increased heart rate in the spinal rat is, in part, a secondary response associated with the vigorous ongoing spinal reflexes present in these rats throughout the day. These reflexes may affect adrenal preganglionic sympathetic neurons, promoting the release of circulating epinephrine that would increase heart rate. In six of the seven anti-NGF Ab-treated rats, we observed a reduction in skeletal muscle and bladder sphincter spasticity during the 2 week survival time. Typically, SCT rats develop hyper-reflexive 
responses within this time that include bladder sphincter spasms and limb muscle contractions during manual compression of the urinary bladder to produce voiding. In the anti-NGF Ab-treated SCT rats, less hindlimb kicking occurred during bladder compression, and the bladder sphincter was not in spasm. The dampened reflexes in the anti-NGF Ab-treated rats may not have stimulated the release of epinephrine adequately to increase heart rate.

The heart rate changes during dysreflexia in our T4 cord transection model would be predicted to result from activation of the baroreceptor reflex. The vigorous bradycardia, despite a smaller increase in arterial pressure that occurred in the rats treated with antibody, could suggest sensitization of some component of the baroreceptor reflex, a change that we have not observed previously (Maiorov et al., 1997a). Such an effect would not likely be caused by a direct action of anti-NGF because it would not have reached any neurons involved in this reflex circuit. Instead it might relate to a mechanism secondary to the antibody treatment such as a greater potential for reflex bradycardia when adrenergic drive to the heart is lower. Alternatively, a vago-vagal reflex initiated by the colon distension itself may have played a greater role in initiating bradycardia when arterial pressure responses were smaller.

\section{Conclusion}

We have provided the first demonstration that blocking the activity of NGF in the injured spinal cord with a neutralizing antibody not only blocks the maladaptive sprouting of smalldiameter primary afferent neurons in the dorsal horn, but also greatly reduces the life-threatening condition autonomic dysreflexia. Together our data reveal a likely mechanism for the etiology of autonomic dysreflexia and a strategy for its prevention. This blockade of intraspinal NGF probably will not adversely affect regeneration or recovery of cord function. Regeneration of the injured cord likely can be promoted by a combination of other neurotrophic agents such as fibroblast growth factor, NT-3, and BDNF (Cheng et al., 1996; Grill et al., 1997a; Menei et al., 1998). Because delivery of growth factors to the injured cord may have deleterious effects such as stimulating the growth of the CGRP-IR afferent fibers (Tuszynski et al., 1996; Grill et al., $1997 b$ ), in addition to beneficial effects, regeneration paradigms must take all possibilities into account.

Blocking the sprouting of the small-diameter, CGRP-IR afferent fibers by developing treatments to neutralize the intraspinal effects of NGF could impede the development of autonomic dysreflexia and markedly improve the quality of life of the cordinjured person. Prevention of the condition would be a more satisfying solution than the treatment of its symptoms with their unpredictable occurrence and severity. Moreover, because primary afferent neurons also play a role in other disabling conditions that develop after cord injury, a treatment to reduce autonomic dysreflexia would likely also block muscle spasticity, urinary bladder dysfunction, and some types of chronic pain (Botterell et al., 1953; McGuire and Brady, 1979; Cohen et al., 1988; Xu et al., 1992; Kruse et al., 1993; Middleton et al., 1996; Yezierski, 1996).

\section{REFERENCES}

Averill S, McMahon SB, Clary DO, Reichardt LF, Priestley JV (1995) Immunocytochemical localization of trkA receptors in chemically identified subgroups of adult rat sensory neurons. Eur J Neurosci 4:1484-1494.

Bakhit C, Armanini M, Wong WLT, Bennett GL, Wrathall JR (1991)
Increase in nerve growth factor-like immunoreactivity and decrease in choline acetyltransferase following contusive spinal cord injury. Brain Res 554:264-271.

Botterell EH, Callaghan JC, Jousse AT (1953) Pain in paraplegia clinical management and surgical treatment. Proc R Soc Med 47:281-288.

Cheng H, Cao Y, Olson L (1996) Spinal cord repair in adult paraplegic rats: partial restoration of hind limb function. Science 273:510-513.

Christensen MD, Hulsebosch CE (1997) Spinal cord injury and antiNGF treatment results in changes in CGRP density and distribution in the dorsal horn in the rat. Exp Neurol 147:463-475.

Christensen MD, Supowit SC, DiPette DJ, Hulsebosch CE (1997) A study of upregulation of gene expression of CGRP and GAP-43 in dorsal root ganglia by spinal hemisection and nerve growth factor. Soc Neurosci Abstr 23:1721.

Clarke HA, Dekaban GA, Weaver LC (1998) Identification of lamina V and VII interneurons presynaptic to adrenal sympathetic preganglionic neurons in rats using a recombinant herpes simplex virus type 1. Neuroscience 85:863-872.

Cohen MJ, McArthur DL, Vulpe M, Schandler SL, Gerber KE (1988) Comparing chronic pain from spinal cord injury to chronic pain of other origins. Pain 35:57-63.

Conner JM, Varon S (1992) Distribution of nerve growth factor-like immunoreactive neurons in the adult rat brain following colchicine treatment. J Comp Neurol 326:347-362.

Constantinou J, Reynolds ML, Woolf CJ, Safieh-Garabedian B, Fitzgerald M (1994) Nerve growth factor levels in developing rat skin: upregulation following skin wounding. NeuroReport 5:2281-2284.

Diamond J, Holmes M, Coughlin M (1992) Endogenous NGF and nerve impulses regulate the collateral sprouting of sensory axons in the skin of the adult rat. J Neurosci 12:1454-1466.

Green SH, Rydel RE, Connolly JL, Greene LA (1986) PC12 cell mutants that possess low- but not high-affinity nerve growth factor receptors neither respond to nor internalize nerve growth factor. J Cell Biol 102:830-843.

Grill R, Murai K, Blesch A, Gage FH, Tuszynski MH (1997a) Cellular delivery of neurotrophin-3 promotes corticospinal axonal growth and partial functional recovery after spinal cord injury. J Neurosci 17:5560-5572.

Grill RJ, Blesch A, Tuszynski MH (1997b) Robust growth of chronically injured spinal cord axons induced by grafts of genetically modified NGF-secreting cells. Exp Neurol 148:444-452.

Heumann R, Lindholm D, Bandtlow C, Meyer M, Radeke MJ, Misko TP, Shooter E, Thoenen H (1987) Differential regulation of mRNA encoding nerve growth factor and its receptor in rat sciatic nerve during development, degeneration, and regeneration: Role of macrophages. Proc Natl Acad Sci USA 84:8735-8739.

Janig W (1996) Neurobiology of visceral afferent neurons: neuroanatomy, functions organ regulations and sensations. Biol Psychol 42:29-51.

Joshi S, LeVatte MA, Dekaban GA, Weaver LC (1995) Identification of spinal interneurons antecedent to adrenal sympathetic preganglionic neurons using trans-synaptic transport of herpes simplex virus type 1. Neuroscience 65:893-903.

Koizumi K, Collin R, Kaufman A, Brooks CM (1970) Contribution of unmyelinated afferent excitation to sympathetic reflexes. Brain Res 20:99-106.

Korsching S, Thoenen H (1983) Nerve growth factor in sympathetic ganglia and corresponding target organs of the rat: correlation with density of sympathetic innervation. Proc Natl Acad Sci USA 80:3513-3516.

Korsching S, Thoenen H (1985) Nerve growth factor supply for sensory neurons: site of origin and competition with the sympathetic nervous system. Neurosci Lett 54:201-205.

Krassioukov AV, Weaver LC (1995) Episodic hypertension due to autonomic dysreflexia in acute and chronic spinal cord-injured rats. Am J Physiol 268:H2077-H2083.

Krenz NR, Weaver LC (1998a) Astrocytes and macrophages are immunoreactive for nerve growth factor following spinal cord injury in rats. Soc Neurosci Abstr 24:743-743.

Krenz NR, Weaver LC (1998b) Sprouting of primary afferent fibers after spinal cord transection in the rat. Neuroscience 85:443-458.

Kruse MN, Belton AL, De Groat WC (1993) Changes in bladder and external urethral sphincter function after spinal cord injury in the rat. Am J Physiol 264:R1157-R1163.

Lee BY, Karmakar MG, Herz BL, Sturgill RA (1994) Autonomic dysreflexia revisited. J Spinal Cord Med 18:75-87. 
Ma W, Ribeiro-Da-Silva A, Noel G, Julien J-P, Cuello AC (1995) Ectopic substance $\mathrm{P}$ and calcitonin gene-related peptide immunoreactive fibres in the spinal cord of transgenic mice over-expressing nerve growth factor. Eur J Neurosci 7:2021-2035.

Maiorov DN, Krenz NR, Krassioukov AV, Weaver LC (1997a) Role of spinal NMDA and AMPA receptors in episodic hypertension in conscious spinal rats. Am J Physiol 273:H1266-H1274.

Maiorov DN, Weaver LC, Krassioukov AV (1997b) Relationship between sympathetic activity and arterial pressure in conscious spinal rats. Am J Physiol 272:H625-H631.

Maiorov DN, Fehlings MG, Krassioukov AV (1998) Relationship between severity of spinal cord injury and abnormalities in neurogenic cardiovascular control in conscious rats. J Neurotrauma 15:365-374.

Mathias CJ, Frankel HL (1992) The cardiovascular system in tetraplegia and paraplegia. In: Handbook of clinical neurology (Frankel HL, ed), pp 435-456. London: Elsevier Science.

Mathias CJ, Frankel HL (1993) Autonomic disturbances in spinal cord lesions. In: Autonomic failure. A textbook of clinical disorders of the autonomic nervous system (Bannister R, Mathias CJ, eds), pp 839-881. Oxford: Oxford Medical.

McGuire EJ, Brady S (1979) Detrusor-sphincter dyssynergia. J Urol 121:774-777.

Meakin SO, MacDonald JIS (1998) A novel juxtamembrane deletion in rat TrkA blocks differentiative but not mitogenic cell signaling in response to nerve growth factor. J Neurochem 71:1875-1888.

Menei P, Montero-Menei C, Whittemore SR, Bunge RP, Bunge MB (1998) Schwann cells genetically modified to secrete human BDNF promote enhanced axonal regrowth across transected adult rat spinal cord. Eur J Neurosci 10:607-621.

Middleton JW, Siddall PJ, Walker S, Molloy AR, Rutkowski SB (1996) Intrathecal clonidine and baclophen in the management of spasticity and neuropathic pain following spinal cord injury: a case study. Arch Phys Med Rehabil 77:824-826.
Osborn JW, Taylor RF, Schramm LP (1990) Chronic cervical spinal cord injury and autonomic hyperreflexia in rats. Am J Physiol 258:R169-R174.

Pittam BS, Ewart WR, Appia F, Wingate DL (1988) Physiological enteric stimulation elicits cardiovascular reflexes in the rat. Am J Physiol 255:G319-G328.

Sato A, Schmidt RF (1973) Somatosympathetic reflexes: afferent fibers, central pathways, discharge characteristics. Physiol Rev 53:916-947.

Sharkey KA, Sobrino JA, Cervero F, Varro A, Dockray GJ (1989) Visceral and somatic afferent origin of calcitonin gene-related peptide immunoreactivity in the lower thoracic spinal cord of the rat. Neuroscience 32:169-179.

Shelton DL, Reichardt LF (1994) Expression of the $\beta$-nerve growth factor gene correlates with the density of sympathetic innervation in effector organs. Proc Natl Acad Sci USA 81:7951-7955.

Sokol RR, Rohlf FJ (1981) Biometry: the principles and practice of statistics in biological research. San Francisco: W.H. Freeman.

Tuszynski MH, Peterson DA, Ray J, Baird A, Nakahara Y, Gage FH (1994) Fibroblasts genetically modified to produce nerve growth factor induce robust neuritic ingrowth after grafting to the spinal cord. Exp Neurol 126:1-14.

Tuszynski MH, Gabriel K, Gage FH, Suhr S, Meyer S, Rosetti A (1996) Nerve growth factor delivery by gene transfer induces differential outgrowth of sensory, motor, and noradrenergic neurites after adult spinal cord injury. Exp Neurol 137:157-173.

Xu X-J, Hao J-X, Aldskogius H, Seiger Å, Wiesenfeld-Hallin Z (1992) Chronic pain-related syndrome in rats after ischemic spinal cord lesion: a possible animal model for pain in patients with spinal cord injury. Pain 48:279-290.

Yezierski RP (1996) Pain following spinal cord injury: the clinical problem and experimental studies. Pain 68:185-194. 